\title{
Development and Clinical Prospects of Techniques to Separate Circulating Tumor Cells from Peripheral Blood
}

This article was published in the following Dove Press journal: Cancer Management and Research

\section{Cheng Tian \\ Xinhua Xu \\ Yuke Wang \\ Dailong $\mathrm{Li}$ \\ Haiyan Lu \\ Ziwei Yang}

Yichang Central People's Hospital, First Clinical Medical College of Three Gorges University, Yichang 443000, People's

Republic of China
Correspondence: Xinhua $\mathrm{Xu}$ First Clinical Medical College of Three Gorges University, Yichang Central People's Hospital, I 80 Yiling Main Road, Yichang 443000, People's Republic of China

Email xuxinhua@medmail.com.cn

\begin{abstract}
Detection of circulating tumor cells (CTC) is an important liquid biopsy technique that has advanced considerably in recent years. To further advance the development of technology for curing cancer, several CTC technologies have been proposed by various research groups. Despite their potential role in early cancer diagnosis and prognosis, CTC methods are currently used for research purposes only, and very few methods have been accepted for clinical applications because of difficulties, including CTC heterogeneity, CTC separation from the blood, and a lack of thorough clinical validation. Although current CTC technologies have not been truly implemented, they possess high potential as future clinical diagnostic techniques for individualized cancer. Here, we review current developments in CTC separation technology. We also explore new CTC detection methods based on telomerase and nanomaterials, such as in vivo flow cytometry. In addition, we discuss the difficulties that must be overcome before CTC can be applied in clinical settings.
\end{abstract}

Keywords: circulating tumor cells, cancer, liquid biopsy, tumor metastasis, cancer diagnosis

\section{Introduction}

Circulating tumor cells (CTC) enter peripheral blood circulation either spontaneously or during cancer treatment. Due to high activity and metastasis potential, CTC are sometimes considered as the primary mechanism of tumor metastasis. ${ }^{1}$ Thus, they are important marker of tumor screening, diagnosis, prognosis, and efficacy evaluation. ${ }^{2-6}$ Therefore, imaging CTC should improve the accuracy of lung cancer screening and early detection. CTC are extremely rare, with only one per 106-107 peripheral blood leukocytes from cancer patients. ${ }^{7}$ Because of their rarity, research on CTC imaging did not emerge until the development of the cell search system, a Food and Drug Administration (FDA)-approved medical device for CTC selection and counting. However, challenges remain in terms of formulating a uniform standard for CTC separation (Table 1). ${ }^{8,9}$

The heterogeneity of CTC is the primary obstacle in their detection. These cells differ in size, shape, and immunotyping across tissue types. For example, during epithelial-to-stromal transformation (EMT), both epithelial cell adhesion molecule (EpCAM) and cytokeratin (CK) are downregulated resulting in failure of conventional EpCAM-based capturing techniques in detecting CTC subpopulations with more mesenchyme-like phenotype. ${ }^{10,11}$ In addition, due to multi-step cell preparation processes, circulating tumor cells may be destroyed and fragmented, resulting in inaccurate test results. ${ }^{7}$ 


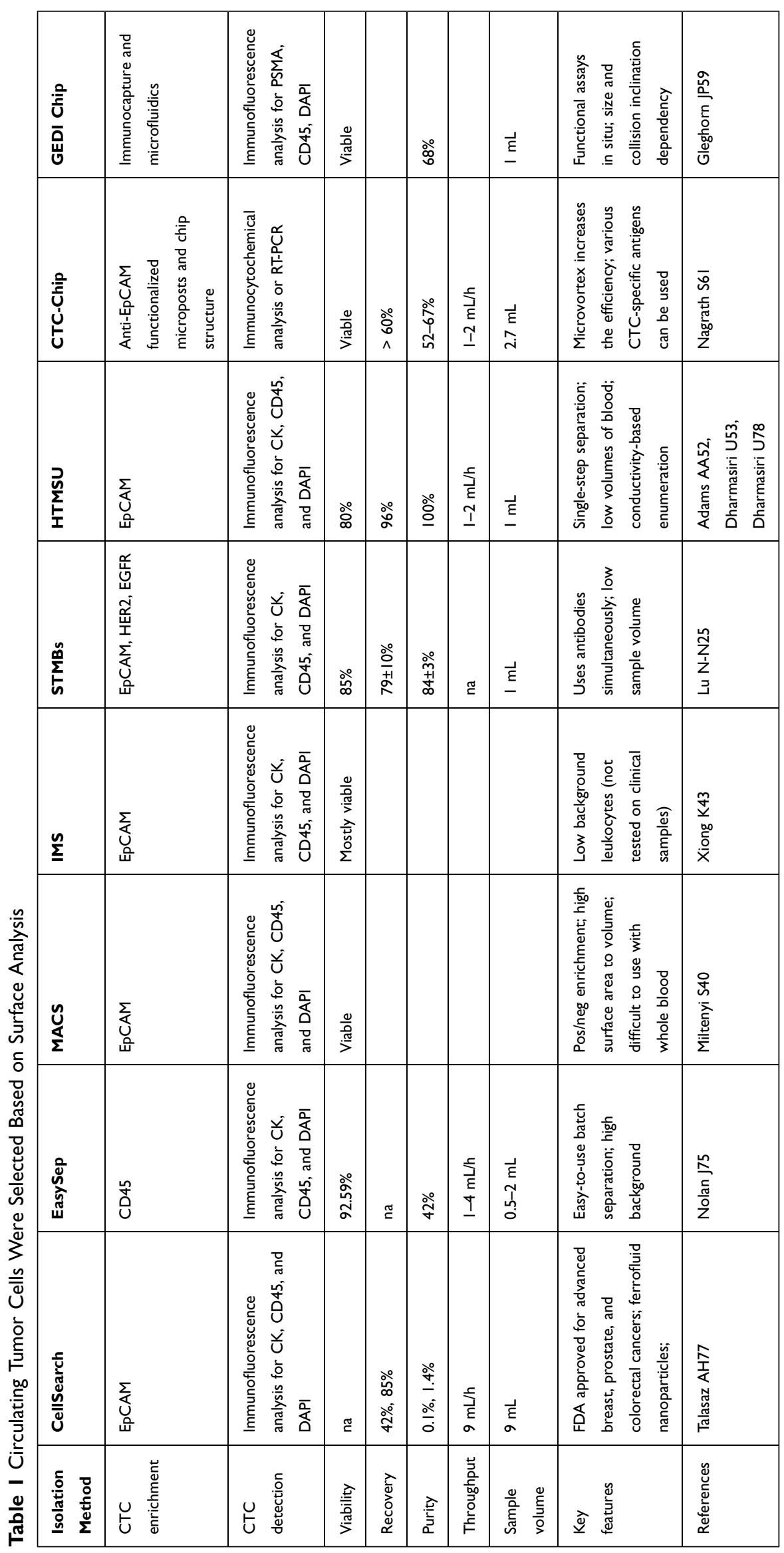


The detection of CTC has three main steps: 1) blood sample preparation for tumor cell separation, 2) antibody staining or DNA probe detection, and 3) imaging of cells. Improved cell separation technology allows us to obtain complete CTC for biological characterization and functional analysis (Figure 1). In this review, we focus on the development of CTC separation technique, particularly the advantages and disadvantages of various separation methods. We then summarize the areas in which separation technique still requires improvement and the current limitations of its clinical application. Finally, we examine the potential future directions of CTC use in clinical settings.

\section{Cell Separation Methods Surface Antigen-Based Separation}

Circulating tumor cells are recognized by their round or oval morphology, along with the presence of surface antigens epithelial cell adhesion molecule (EpCAM) and cytokeratin (CK), as well as the absence of CD45. ${ }^{12}$ Separation methods using surface antigens can be divided into positive and negative selection. The most representative positive-selection method is the cell search system. Negative selection generally involves removing unnecessary cells to indirectly capture
CTC. For example, all CD45+ peripheral blood cells can be excluded to leave only the CD45-CTC. However, this method usually leads to low purity. ${ }^{13-16}$ Another technique called as EasySep (developed by Stemcell) is an immunomagnetic method that separates CTC through negative enrichment using a mixture of CD45-containing antibodies and differently sized magnetic beads. With an average recovery of $42.23 \%$, EasySep can produce living cells without markers and also be used for subsequent downstream analysis.

The prognosis of patients with breast, prostate, or colorectal cancers is related to CTC count. ${ }^{17-19}$ After revealing this potential, the FDA approved the cell search system as the only technology for clinical CTC detection. This immunocytochemistry method is based on magnetic immunity and staining. First, EpCAM antibody beads are used to enrich CTC, which are then extracted from blood under a strong magnetic field. Next, tumor cells are fixed and identified through fluorescent-stained keratin. A semiautomatic four-color fluorescence microscope is used to detect stained cells, and those with the tumor cytological characteristics are identified as CTC. ${ }^{20}$ However, a related method is superior to simply using EpCAM antigen to enrich $\mathrm{CTC}^{21}$ at least in case of lung cancer. Because

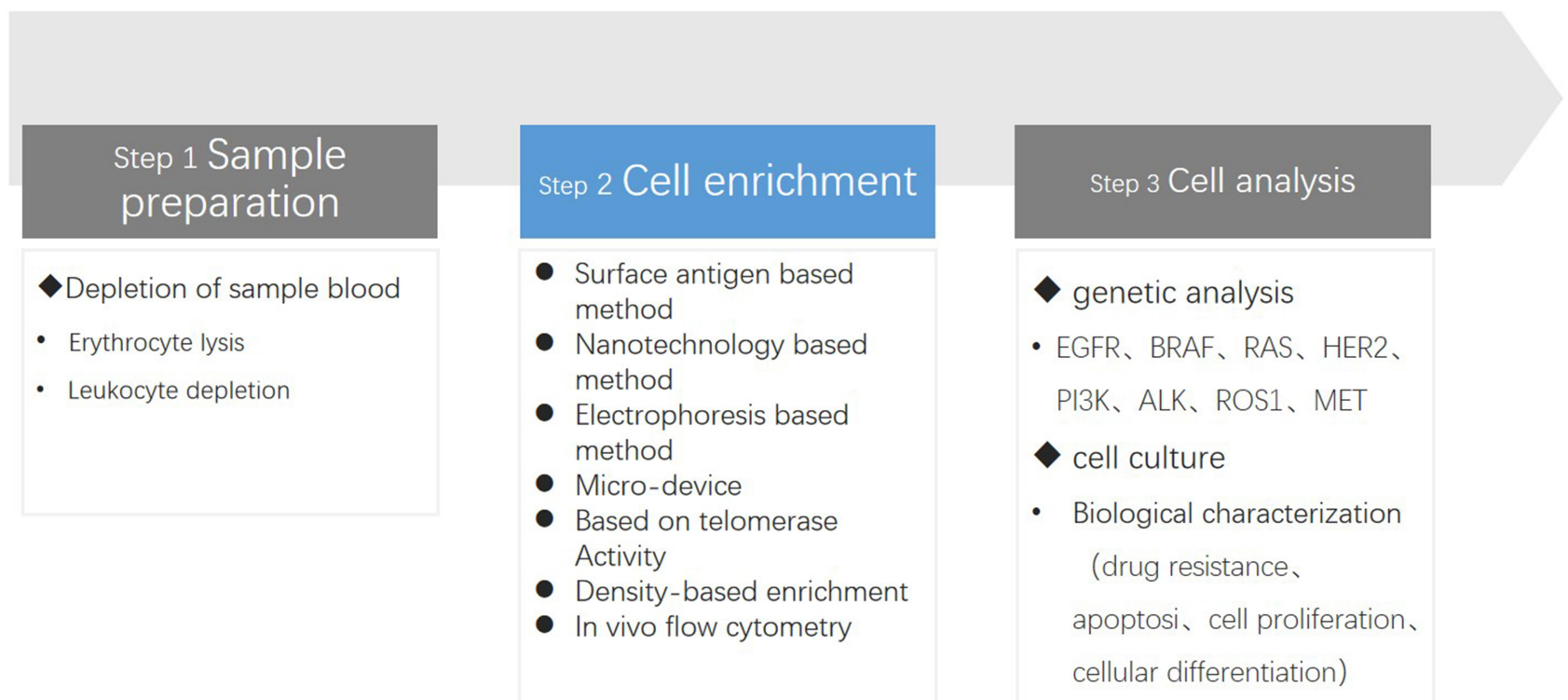

Figure I Graphic illustration of three major steps in a CTC assay. Step I. Sample preparation: in order to isolate and detect CTCs at a high frequency, the blood sample should be pretreated to remove the erythrocytes and/or leukocytes as much as possible to provide a low interference background. Step 2 . Cell enrichment: CTC can be detected by multiple methods, depending on the different theories, they are divided into seven groups: surface antigen based, physical property based, nanotechnology based, electrophoresis based, micro-devices, telomerase, Density-based and in vivo flow cytometry. Step3. Cell analysis: At present, the research on the biological characteristics and functional analysis of circulating tumor cells mainly involves two aspects: genome/transcriptome analysis and in vitro culture. We can be understood through genetic analysis to guide clinical treatment, and by vitro culture can further understand the biological characteristics of CTC. 
EpCAM is expressed mostly in lung cancers that originate from epithelial cells, anti-EpCAM antibodies can be used in CTC, and profile kits to detect CTC in peripheral blood. However, the use of CellSearch device for CTC detection was discontinued a long time ago owing to severe problems in clinical application.

Another surface antigen useful for CTC analysis is melanoma cell adhesion molecule (MCAM). When used in combination with EpCAM as a cell-search enrichment marker, CTC detection rate is improved from $18 \%$ (EpCAM only) to $25 \% .^{22}$ However, we require more data to conclude whether changes to MCAM+ CTC during localized or metastatic cancer treatment are related to clinical outcomes.

A recently developed method uses $M E T$ gene to detect amplified tumor cells in a rapid, noninvasive, sensitive, and specific way. ${ }^{23} c-M E T$ is a protein product encoded by the MET proto-oncogene, which is a hepatocyte growth factor receptor with tyrosine kinase activity and is associated with a variety of oncogene products and regulatory proteins. The sensitivity of this method to the cells highly expressing $C M E T$ was $40-80 \%$, and specificity to $C M E T$-negative cells was $100 \%$. Given that CMET+ CTC and MET amplification are highly correlated, the former is a potential biomarker for predicting individualized treatment for patients with cancers that highly express CMET (eg, gastric, colorectal, and renal cancers). Technologies using other surface markers (eg, EGFR, HER2, and MUC1) have also been developed, along with antibodies that target stem cells and stromal markers. ${ }^{24}$ In the integrated immunomagnetic separation system, chemical coupling is used to prepare Strep-tag-II-derived immunoglobulin G (IgG). This is then reversibly loaded on Strep-tag-combined magnetic beads (stmbs) to fix antibodies, including anti-EpCAM, anti$H E R 2$, and anti-EGFR. Using different antibodies that can capture more CTC subgroups simultaneously, the technique results in high capture efficiency (79\%) for IgG stmbs. ${ }^{25}$

Epithelial markers, such as CK 8, 18, 19, and EpCAM, are the commonly used biomarkers for CTC identification, although they could identify only tissue origin and not the biological behavior (benign vs malignant). It is known that tumor cells could decrease or lose epithelial marker expression during metastasis/dissemination, causing significant heterogeneity, however, researchers have not been able to identify a universal tumor antigen which can trap all potential CTC that fail to express epithelial markers. ${ }^{7}$ This limitation invalidates the CTC immunomagnetic enrichment and staining procedures, reducing the application of cell search systems in several cancers, including lung, gastric, and liver. ${ }^{11,25,26}$ In addition, only the screening and isolation tables would be available for any cancers that affect the epithelial-to-stromal transformation, because surface antigens such as EpCAM, keratin, MCAM, and c-Met may cease being expressed during this process. However, negative selection enrichment has the disadvantage of potential contamination by CD45 + cells that are not completely separated, lowering the sample specificity and purity. However, further cleaning would cause cell destruction and fragmentation, thereby increasing the cost while reducing the efficiency.

\section{Telomerase-Based Detection}

Recent research has identified a special reverse transcriptase in tumor cell nuclei that increases telomere length repeatedly. This characteristic suggests that the reverse transcriptase, or the telomerase, may be a potential biomarker and prognostic indicator of tumors. Telomerase activity is reactivated in almost all the tumor cells, but never in normal cells. $^{27}$ Therefore, telomerase activity should be a viable option for detecting CTC in cancers without EpCAM expression, including prostate, bladder, colon, breast, and brain cancers. ${ }^{28}$ For example, while most of the available methods cannot detect CTC in prostate cancer, analysis of telomerase activity successfully achieved high detection rate (75\%) and specificity (100\%). ${ }^{29}$ Telomerase activity has also been successfully used to identify $100 \%, 84 \%, 73 \%$, and $90 \%$ of patients with stage IV ovarian cancer, ${ }^{30}$ stage IV breast cancer, ${ }^{31}$ stage IIIB/IV NSCLC (no small cell lung cancer), ${ }^{32}$ and metastatic bladder cancer, ${ }^{31}$ respectively. However, the telomere-based method has a major limitation in that the peripheral blood cells must be split, precluding any other further analysis. ${ }^{33}$

\section{Electrophoresis-Based Separation}

The electrophoretic method involves using dielectrophoresis (DEP) field flow to isolate CTC from normal peripheral blood cells through their morphological and biophysical differences (eg, membrane capacitance, shape, size, and conductivity). ${ }^{34}$ Previous studies have shown that differences in conductivity between normal blood cells and CTC depend on the effective surface area of the cell membrane, which in turn influences the membrane capacitance. ${ }^{35}$ Isolating cells with different dielectric phenotypes using DEP clarifies the range in conductivity between cancer cells and normal blood cells (Table 2). ${ }^{36}$ Another study proposed the use of staggered electrode 
Table 2 Circulating Tumor Cells Were Selected Based on DEP

\begin{tabular}{|c|c|c|c|c|c|c|}
\hline $\begin{array}{l}\text { Isolation } \\
\text { Method }\end{array}$ & eDEP & TWDEP & CDEP & iDEP & Optical DEP & $\begin{array}{l}\text { Two Steps } \\
\text { Separation Methods }\end{array}$ \\
\hline $\begin{array}{l}\text { CTC } \\
\text { enrichment }\end{array}$ & $\begin{array}{l}\text { Dielectrophoresis } \\
\text { field-flow assist } \\
\text { principles }\end{array}$ & & $\begin{array}{l}\text { Dielectrophoretic } \\
\text { field }\end{array}$ & Dielectrophoretic field & $\begin{array}{l}\text { Dielectrophoretic } \\
\text { field }\end{array}$ & $\begin{array}{l}\text { Dielectrophoretic field } \\
\text { and microfluidic }\end{array}$ \\
\hline $\begin{array}{l}\text { СТC } \\
\text { detection }\end{array}$ & $\begin{array}{l}\text { Immunofluorescence } \\
\text { analysis for ASPL- } \\
\text { TFE3 type I fusion } \\
\text { protein and vimentin }\end{array}$ & & & & & $\begin{array}{l}\text { Immunofluorescence } \\
\text { analysis, PCR and } \\
\text { sequencing methods }\end{array}$ \\
\hline Viability & 0.9 & Viable & Viable & Viable & Viable & Viable \\
\hline Recovery & 0.85 & & 0.8 & 0.75 & 0.71 & na \\
\hline Purity & 0.9 & & Low & Low & 0.92 & High \\
\hline Throughput & $5 \mathrm{~mL} / 2 \mathrm{~h}$ & & $2.2 \mathrm{~mL} / \mathrm{h}$ & na & High & na \\
\hline $\begin{array}{l}\text { Sample } \\
\text { volume }\end{array}$ & & & na & na & na & na \\
\hline $\begin{array}{l}\text { Key } \\
\text { features }\end{array}$ & $\begin{array}{l}\text { Separated by } \\
\text { electrophoresis; } \\
\text { demonstrated by } \\
\text { fluorescence in situ } \\
\text { hybridization }\end{array}$ & & $\begin{array}{l}\text { The absence of } \\
\text { contact between } \\
\text { the electrodes and } \\
\text { the media }\end{array}$ & $\begin{array}{l}\text { Single-cell trapping; } \\
\text { separation based on } \\
\text { the cell size and } \\
\text { electrophoresis; } \\
\text { a high-throughput } \\
\text { method }\end{array}$ & $\begin{array}{l}\text { Size-based } \\
\text { separation; higher } \\
\text { resolution of the } \\
\text { cell separation }\end{array}$ & $\begin{array}{l}\text { Requires CD45 } \\
\text { depletion and manual } \\
\text { staining; Different } \\
\text { antigens can be used for } \\
\text { immunofluorescence } \\
\text { analysis }\end{array}$ \\
\hline References & $\begin{array}{l}\text { Chan, }^{79}{ } \text { Vykoukal }^{80} \text {, } \\
\text { Huang, }{ }^{81} \text { Moon, }{ }^{82} \\
\text { Cheng }\end{array}$ & $\mathrm{Cen}^{84}$ & Zhao $^{85}$ & Kang $^{86,}$ Bhattacharya ${ }^{87}$ & $\begin{array}{l}\text { Chuang, }{ }^{88} \mathrm{Wu}^{89} \text {, } \\
\text { Qin }^{90}\end{array}$ & Huang $^{91}$, Huang $C^{92}$ \\
\hline
\end{tabular}

structure to capture CTC, resulting in $92 \%$ efficiency in isolating human lung cancer cell line NCI-H1975 at high flux (flow rate of $6 \mathrm{~mL} / \mathrm{h}$ ). ${ }^{37}$ A study isolating CTC using side electrophoresis processed $5 \mathrm{~mL}$ of samples continuously within $2 \mathrm{~h}$, with $85 \%$ recovery rate and $>90 \%$ CTC purity. ${ }^{38}$ Finally, two-dimensional electrophoresis successfully isolated human breast cancer cells and colorectal cancer cells.

Taken together, these results showed that DEP is capable of screening normal blood cells, tumor cells, malignant cell clusters, and malignant cell groups with different heterogeneity in peripheral blood. However, DEP also has obvious disadvantages. Processing time is too long, resulting in low efficiency. In addition, inappropriate cell concentration in samples easily causes contamination of CTC from normal cells, reducing purity. Finally, the specific buffer used by DEP has a strong correlation with cell survival rate, suggesting a strong confounding factor that would influence interpretation of results.

\section{Nanotechnology-Based Separation}

Nanoparticles are similar in size to cell membrane pores. Additionally, covering nanoparticles with CTC-specific antibody can increase the surface area for CTC binding. These characteristics suggest that techniques using nanoparticles can promote cellular interaction, enhance cell adhesion, and isolate CTC, greatly improving efficiency, purity, sensitivity, and repeatability in malignant cell capture. In the past few decades, nanotechnology research has greatly advanced, resulting in tools such as the multifunctional immunomagnetic nano carrier platform (Table 3). However, nanotechnology methods also suffer from high contamination from normal blood cells. To address this issue of high contamination, Wang et $\mathrm{al}^{39}$ developed a CTC capture platform that combines silicon dioxide nanoparticles (SINP) with antibodies. The platform has anti-Epcam-coated SINP substrate and a PDMS (polydimethylsiloxane) chip to increase cellular surface area. The PDMS chip also has a serpentine mixed channel that promotes CTC and lining. 
Table 3 Circulating Tumor Cells Were Selected Based on Chip

\begin{tabular}{|l|l|l|l|}
\hline $\begin{array}{l}\text { Isolation } \\
\text { Method }\end{array}$ & GO Chip & SiNP Platform & NP-HBCTC-Chip \\
\hline CTC enrichment & EPCAM & EpCAM & EPCAM, HER2, EGFR, or cocktail \\
\hline CTC detection & $\begin{array}{l}\text { Immunofluorescence analysis for } \\
\text { CK, CD45, and DAPI }\end{array}$ & $\begin{array}{l}\text { Immunofluorescence analysis for CK, CD45, and } \\
\text { DAPI }\end{array}$ & $\begin{array}{l}\text { Immunofluorescence analysis for } \\
\text { CK, CD45, and DAPI }\end{array}$ \\
\hline Viability & 0.92 & & $87-93 \%$ \\
\hline Recovery & $91-95 \%$ & 0.95 & $91-92 \%$ \\
\hline Purity & High & & I mL/h \\
\hline Throughput & I-3 mL/h & I mL/h & $3.5 \mathrm{~mL}$ \\
\hline Sample volume & $\mathrm{I} \mathrm{mL}$ & $\mathrm{I} \mathrm{mL}$ & $\begin{array}{l}\text { Antibody-coated gold nanoparticles } \\
\text { for capture enhancement }\end{array}$ \\
\hline Key features & $\begin{array}{l}\text { Graphene oxide nanosheets; } \\
\text { easy fabrication; high purity }\end{array}$ & $\begin{array}{l}\text { Antibody-coated silicone nanopillars for capture } \\
\text { enhancement; I.5-3.0-psi pressure }\end{array}$ & Park \\
\hline References & Yoon & Wang & \\
\hline
\end{tabular}

Another enrichment technology based on immunomagnetic nanoparticles is the magnetic cell separation system (MACS). ${ }^{7,40}$ This method involves high-gradient magnetic separation to capture CTC that are labeled using magnetic nanoparticles coupled with EpCAM antibodies. Although there are studies using MACS to capture CTC from peripheral blood of metastatic cancer patients, ${ }^{41,42}$ the technique is more suitable for tissue samples than for whole blood samples. ${ }^{43}$ Biomimetic immunomagnetics (IMS) were introduced recently to address the problem of poor MACS detection in whole blood. This technology formed magnetic corpuscles through camouflage magnetic nanoclusters with white blood cell membrane fragments. As a result, adsorption of non-specific white blood cells in peripheral blood samples was inhibited, reducing the contamination of CTC by background cells. Although this equipment has not been tested in a clinical setting, experiments revealed a near-complete lack of background cells, as a major advantage. ${ }^{43,44}$

The use of immunomagnetic nanocarriers can achieve high capture rates in cancers lacking EpCAM expression. ${ }^{45}$ Moreover, the different nano-materials available for linings (eg, quartz, ${ }^{46}$ polymers, ${ }^{47}$ and gold $^{48}$ ) allow flexibility that improve CTC capture efficiency of EpCAM-expressing cancers and detection efficiency of low EpCAM-expressing malignant tumors. The recently developed nanoparticle HBCTC chip can be coated with surface markers including EpCAM, HER2, and EGFR, or a mixture of the three, achieving $>90 \%$ capture efficiency for low EpCAM-expressing cells (such as the MDA-MB -231 line). The thiol exchange reaction then releases captured cells from nanoparticles, allowing for subsequent CTC molecular analyses, such as next-generation RNA sequencing and cell culture. ${ }^{49,50}$

Methods that improve nanomaterial adhesion to cancer cells over normal cells include a nano-surface subjected to reactive ion etching. ${ }^{51}$ The nanotube array has also been developed as a sensitive biodetector for CTC detection. Compared with an anti-EpCAM-modified planar substrate, the anti-EpCAM-modified conducting polymer nanotube has a CTC capture rate of $70 \%$ and a cell survival rate of $97 \%$.

Although nanotechnology has significantly improved capture efficiency, little data are available on how nanostructured substrates influence the interaction between tumor cells and normal peripheral blood cells. Moreover, the purity of CTC extracted via nanomaterials still needs improvement.

\section{Micro-Device-Based Separation}

Micro-devices are any tools created through microprocessing technology and chemical synthesis for specific molecular biological test functions in a very small area. Numerous studies show that micro-devices have short processing time, simple operation, and high separation efficiency. $^{7}$ Currently available micro-devices include the microsingular chip, ${ }^{52,53}$ microfilter, ${ }^{54-56}$ micro EDAR (sensitive decision aliquot ranking) cytometer, ${ }^{57}$ and microGEDI (geometrically enhanced differential 


\begin{tabular}{|c|c|c|c|c|c|c|c|c|}
\hline $\begin{array}{l}\text { 弇 } \\
\text { 章总 }\end{array}$ & & & & & 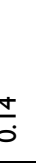 & 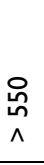 & $\underline{\underline{E}}$ & $\begin{array}{l}m_{\infty 00}^{\infty} \\
\sum_{50}^{5} \\
3\end{array}$ \\
\hline 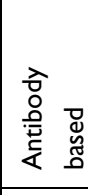 & $\stackrel{\text { مू }}{\circ}$ & & & & 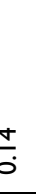 & 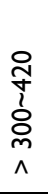 & $\begin{array}{l}\vec{E} \\
\vec{\sigma}\end{array}$ & 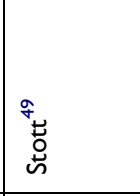 \\
\hline 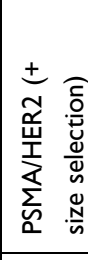 & б. & & & & $\bigsqcup_{6}^{\circ}$ & $\begin{array}{l}\text { 员 } \\
\wedge\end{array}$ & $\underline{\vec{\varepsilon}}$ & 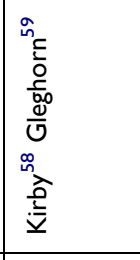 \\
\hline 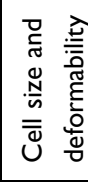 & & & & & $\llbracket$ & 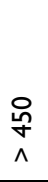 & $\underline{\vec{\varepsilon}}$ & 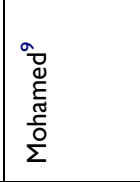 \\
\hline 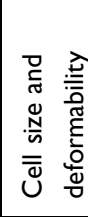 & $\stackrel{\infty}{\circ}$ & & & & 我 & 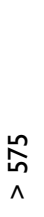 & $\begin{array}{l}\overrightarrow{\underline{E}} \\
\underline{\underline{I}}\end{array}$ & 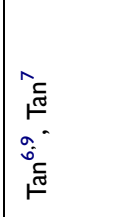 \\
\hline 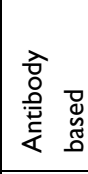 & î. & & & & 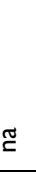 & 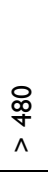 & $\underline{\vec{E}}$ & 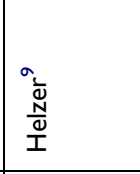 \\
\hline 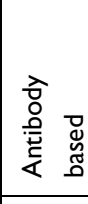 & 今े & & & & $\frac{\delta_{0}^{\circ}}{\frac{1}{n}}$ & $\stackrel{8}{\stackrel{2}{\Lambda}}$ & $\begin{array}{l}\vec{E} \\
\sigma\end{array}$ & 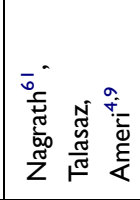 \\
\hline 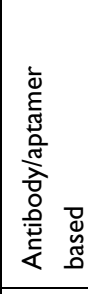 & 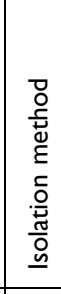 & & & $\hat{~}$ & - & & $\underline{\vec{E}}$ & 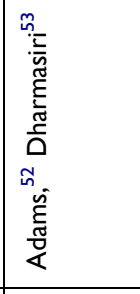 \\
\hline$\frac{\stackrel{ \pm}{\tilde{n}}}{\overline{\bar{u}}}$ & $\stackrel{\substack{\infty \\
0}}{0}$ & & & & 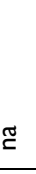 & $\frac{\mathcal{Z}}{\Lambda}$ & $\begin{array}{l}\vec{E} \\
\stackrel{\vec{E}}{n}\end{array}$ & 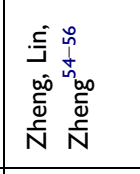 \\
\hline 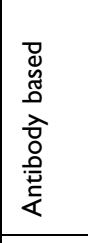 & & & & & 䓪 & 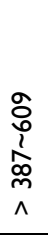 & $\begin{array}{l}\vec{E} \\
\stackrel{\vec{N}}{ }\end{array}$ & 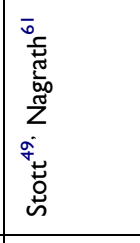 \\
\hline 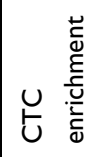 & u & & & & & 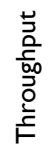 & 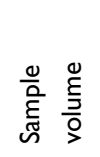 & 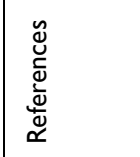 \\
\hline
\end{tabular}


immunocapture) chip (Table 4). ${ }^{58,59}$ Among these, the high-throughput microsampling unit is a microfluidic device that uses surface-immobilized monoclonal antibodies to separate CTC from the blood. The device releases unlabeled live CTC via trypsin. ${ }^{52}$ Next, the CTC chip promotes antibody attachment through geometrical arrangement of 78,000 anti-EpCAM antibody microcolumns with the surface area of $\sim 970 \mathrm{~mm}^{2} 60$ and fluid flow rate. ${ }^{61}$ Gedi combines positive enrichment (using antibody-coated microcolumn) with hydrodynamic chromatography to maximize the streamline distortion of its geometry, reducing non-specific leukocyte adhesion and capturing high-purity CTC. ${ }^{59}$ In comparison to the detection sensitivity of the cell search system (96\%), microfilter, ${ }^{55}$ microGEDI chip, ${ }^{58}$ and microedar cell analyzer $^{57}$ have sensitivities of $75 \%, 94 \%$, and $100 \%$, respectively, whereas these four methods have specificities of $16 \%, 22 \%, 0 \%$, and $0 \%$.

Micro-devices benefit CTC biological characterization as they maintain high efficiency and purity, while they also ensure CTC integrity and activity. We note that microdevices using surface antigen recognition have higher purity than the cell search system, but require more processing time. However, neither method can recognize CTC without related surface antigens, meaning that they will lose key malignant cells. Additionally, size-based CTC-screening micro-devices have faster processing speed than cell search systems, but insufficient purity. Though including the deformability parameters in size-based screening can further improve the purity, this increase is limited.

Microfluidics have also been combined with aptamers, single-stranded RNA, DNA, or peptide molecules with high specificity and affinity for specific target molecules to improve the purity. But these technologies have significant limitations. Screening requires a median of $\sim 10$ h. This longer processing time may affect the CTC survival, as well as the stability of cellular immunophenotype and genotyping. Thus, micro-devices may not be conducive for further CTC research.

\section{Separation Based on Differences in Cell Density}

Separating cells based on buoyancy is one of the oldest isolation methods. Also called as density gradient centrifugation or equal density gradient centrifugation. ${ }^{7}$ Buoyancy-based methods have the advantages of low cost, simple to operate, and independent of specific antigen expression. Whole blood can be divided into three layers: plasma layer, denuclearized cell layer, and CTC layer. ${ }^{62}$ However, these methods have low efficiency and purity of this method is low due to a large number of hematopoietic monocytes. The development of Oncoquick with a porous membrane ${ }^{63}$ improved recovery rate to $87 \%$. ${ }^{64}$ CTC purity still remains very low using buoyancy-based techniques, barely reaching to $1 \%$, even with the most advanced versions. A new centrifugal microfluidics platform was developed to address such problems. First, CTC were bound to anti-EpCAM-labeled beads to distinguish them from normal blood cells. Next, CTC were precipitated and separated under the density gradient medium, thereby improving the separation purity. Despite an improvement through the use of EpCAM, the lack of a standardized CTC density range may still result in CTC being lost during extraction. ${ }^{66}$

Another buoyancy-based device is the Accucycle system. Through a unique separation tube, blood is separated into three layers hematocrit, plasma, white blood cells, and platelets. The CTC are processed with row classification in the Cytefinder, an automatic scanning digital microscope and image analysis system. The average recovery rate of tumor cells is $90 \%$ using this method. Clinical trials reveal that after CTC enrichment, Accucycle can be used for genome analysis of a single CTC. ${ }^{64}$

The main advantage of buoyancy-based CTC separation is simplicity, resulting in viable cells that can be used for subsequent downstream experiments. These methods are also cost-effective and do not require much enrichment time. However, buoyancy-based methods are highly prone to contamination by other peripheral blood cells. In addition, the size and density range of different CTC subtypes are unknown, meaning that some CTC may not be detected.

\section{Separation Based on Cell Size}

Cell-size-based methods mainly involve microfiltration and therefore do not depend on surface antigen expression. ${ }^{67}$ ISET is the most suitable representative of these techniques. $^{68}$ In ISET, pre-fixed peripheral blood is filtered using an $8 \mu \mathrm{m}$ pore membrane. Next, CTC are immunostained for cell counting and morphological analysis. Enrichment of CTC was identified using ISET, mixed with epithelial and stromal phenotypes in the peripheral blood of NSCLC patients for the first time. ${ }^{69}$ This outcome further demonstrated the significance of EMT and the mechanism of metastasis. Another study using ISET detected CTC in 31 
patients with uveal melanoma by ISET, along with a single CTC or CTC cell cluster in 17 others. These results confirmed that CTC predicts poor prognosis in patients with uveal melanoma. Although not all the CTC are larger than normal blood cells, ISET has a $>90 \%$ capture rate. Another major advantage is that ISET can separate epithelial cells without destroying cell morphology. ${ }^{68}$ However, it and the other cell-size-based methods may miss the smaller tumor cells. More research using different cell lines and tumor types are required to determine the application scope and size threshold of ISET. In addition, the technique's specificity and purity must be increased.

\section{In vivo Flow Cytometry}

In vivo flow cytometry (IVFC) allows the quantitative analysis of circulating cells. The technique involves laser scanning of surface blood vessels to detect cells via various visualization methods, including fluorescence excitation and emission, photoacoustic effects, and photothermal effects. $^{70}$ The biggest advantage of IVFC is that the blood collection and treatment are not required. ${ }^{71,72}$ At present, fluorescent and photoacoustic IVFC are the most widely used. $^{73}$ Fluorescent IVFC is approximately 1.8 times more sensitive than conventional whole blood flow cytometry. ${ }^{72}$ This technique helps to identify the effects of other treatments, through fluorescence IVFC, as in case where sorafenib was revealed to reduce CTC count and lung metastasis in patients with advanced liver cancer. ${ }^{74}$ Another study has used IVFC to observe the interactions between circulating breast cancer cells and dendritic cells. Mixed fluorescence and photoacoustic IFVC was also used successfully to detect GFP + breast cancer cells $^{75}$ and to identify apoptotic CTC in vivo. After androgen deprivation therapy, patients with prostate cancer were monitored using IVFC, revealing that the therapy reduced CTC count in peripheral blood. One use of fluorescent IVFC in an orthotopic liver cancer transplantation model and subcutaneous prostate cancer model demonstrated that the number of CTC clusters increased with primary tumor development. Thus, IVFC allowed researchers to confirm the key role of CTC clusters in tumor metastasis.

Nevertheless, IVFC has a clear disadvantage: its detection speed is $1 \mu \mathrm{L} / \mathrm{min}^{76}{ }^{76}$ while $\sim 5 \mathrm{~L} / \mathrm{min}$ blood passes through human blood vessels. Therefore, IVFC is too slow for clinical needs. However, as seen in the examples provided, this technique is particularly useful for CTC detection and counting, which should be valuable for clinical monitoring and prognosis evaluation. The fact that CTC in circulating blood are not purified means that IVFC is not conducive to the detection of CTC molecular typing and the study of biological characteristics.

\section{Conclusions}

The detection and isolation of CTC have progressed in recent years. Advancements have been mainly driven by interdisciplinary research involving cancer biology, oncology, cell physics, materials science, chemistry, nanotechnology, and bioengineering. The diversification of CTC detection methods greatly improved the efficiency and reduced the cost. Unfortunately, every available detection method has major flaws. The cell search system involving surface antigen screening and enrichment possess the ease of automation and high specificity. Yet its clinical application has been hindered by low sensitivity and inability to detect all cancer types. In addition, most current CTC isolation methods require multi-step cell preparation, leading to CTC loss or damage, thus adversely affecting detection efficiency, accuracy, and sensitivity. The difficulty of extracting complete and viable CTC means further analysis is frequently impossible, thereby limiting the utility of these techniques for clinical decision-making.

The availability of high-throughput DNA sequencing means the whole genome and transcriptome of a single CTC can be obtained. These data allow increased attention to CTC biological characteristics, along with more exploration of genetic informatics and phenotypic functions (eg, through genome/transcriptome analysis and in vitro culture). These experiments require high molecular integrity and cell survival rate of isolated CTC, highlighting the importance of improving CTC separation technology. Therefore, future research on CTC detection should first focus on acquiring basic knowledge on CTC, specifically understanding the phenotypic changes accompanying the epithelial-stromal transformation. Insight into this process will help researchers improve the CTC separation efficiency, survival rate, and integrity while developing new methods. Additionally, new capture mechanisms should be explored to reduce blood cell contamination while improving survival and molecular integrity of purified CTC. Finally, antigen markers should be combined to increase cell-capture specificity and solve the issue of CTC heterogeneity. We also require in-depth research to address the experimental protocols, such as determination of detection timing and cut-off values, as well as standardization of specific techniques. Finally, we recommend 
investigations to clarify the consistency of CTC biological characteristics.

Although there are problems to be solved, CTC analysis is a simple and feasible liquid biopsy technology that has gained serious attention and has achieved major success. With further development, CTC-based diagnosis should have considerable value in individualized treatment of patients with cancer.

\section{Acknowledgments}

This study was funded by Hubei natural science foundation project (2011CDB330, 2014CFB312) and Hubei provincial health department research project (JX4B52).

\section{Disclosure}

Xinhua Xu reports a licensed patent (ZL201920055267.9): A special petri dish for magnetic trap. The authors report no other potential conflicts of interest in this work.

\section{References}

1. Strilic B, Offermanns S. Intravascular survival and extravasation of tumor cells. Cancer Cell. 2017;32(3):282-293. doi:10.1016/j. ccell.2017.07.001

2. Sharma S, Zhuang R, Long M, et al. Circulating tumor cell isolation, culture, and downstream molecular analysis. Biotechnol Adv. 2018;36 (4):1063-1078. doi:10.1016/j.biotechadv.2018.03.007

3. Paget S. Paget,Stephen paper reproduced from the Lancet, 1889. Cancer Metastasis Rev. 1989;8(2):98-101.

4. Wiley HE, Gonzalez EB, Maki W, Wu MT, Hwang ST. Expression of CC chemokine receptor-7 and regional lymph node metastasis of B16 murine melanoma. J Natl Cancer Inst. 2001;93(21):1638-1643. doi:10.1093/jnci/93.21.1638

5. Ming Y, Li Y, Xing H, et al. Circulating tumor cells: from theory to nanotechnology-based detection. Front Pharmacol. 2017;8.

6. Esmaeilsabzali H, Beischlag TV, Cox ME, Parameswaran AM, Park EJ. Detection and isolation of circulating tumor cells: principles and methods. Biotechnol Adv. 2013;31(7):1063-1084. doi:10.1016/j. biotechadv.2013.08.016

7. Ferreira MM, Romani VC, Jeffrey SS. Circulating tumor cell technologies. Mol Oncol. 2016;10(3):374-394. doi:10.1016/j. molonc.2016.01.007

8. Bunger S, Zimmermann M, Habermann JK. Diversity of assessing circulating tumor cells (CTCs) emphasizes need for standardization: a CTC Guide to design and report trials. Cancer Metastasis Rev. 2015;34(3):527-545. doi:10.1007/s10555-015-9582-0

9. Krebs MG, Hou J-M, Ward TH, Blackhall FH, Dive C. Circulating tumour cells: their utility in cancer management and predicting outcomes. Ther Adv Med Oncol. 2010;2(6):351-365. doi:10.1177/ 1758834010378414

10. Wicha MS, Hayes DF. Circulating tumor cells: not all detected cells are bad and not all bad cells are detected. J Clin Oncol. 2011;29 (12):1508-1511. doi:10.1200/JCO.2010.34.0026

11. Allard WJ, Miller MC, et al. Tumor cells circulate in the peripheral blood of all major carcinomas but not in healthy subjects or patients with nonmalignant diseases. Clin Cancer Res. 2004;10:6897-6904. doi:10.1158/1078-0432.CCR-04-0378
12. Tibbe AGJ, Miller MC, Terstappen LWMM. Statistical considerations for enumeration of circulating tumor cells. Cytometry Part A. 2007;71A(3):154-162. doi:10.1002/cyto.a.20369

13. Hvichia GE, Parveen Z, Wagner C, et al. A novel microfluidic platform for size and deformability based separation and the subsequent molecular characterization of viable circulating tumor cells. Int J Cancer. 2016;138(12):2894-2904. doi:10.1002/ijc.30007

14. Yang L, Lang JC, Balasubramanian P, et al. Optimization of an enrichment process for circulating tumor cells from the blood of head and neck cancer patients through depletion of normal cells. Biotechnol Bioeng. 2009;102(2):521-534. doi:10.1002/bit.22066

15. Lara O, Tong XD, Zborowski M, Chalmers JJ. Enrichment of rare cancer cells through depletion of normal cells using density and flow-through, immunomagnetic cell separation. Exp Hematol. 2004;32(10):891-904. doi:10.1016/j.exphem.2004.07.007

16. Baccelli I, Schneeweiss A, Riethdorf S, et al. Identification of a population of blood circulating tumor cells from breast cancer patients that initiates metastasis in a xenograft assay. Nat Biotechnol. 2013;31(6):539-U143. doi:10.1038/nbt.2576

17. Hayes DF. Circulating tumor cells at each follow-up time point during therapy of metastatic breast cancer patients predict progression-free and overall survival. Clin Cancer Res. 2006;12 (14):4218-4224. doi:10.1158/1078-0432.CCR-05-2821

18. Danila DC, Heller G, Gignac GA, et al. Circulating tumor cell number and prognosis in progressive castration-resistant prostate cancer. Clin Cancer Res. 2007;13(23):7053-7058. doi:10.1158/ 1078-0432.CCR-07-1506

19. Cohen SJ, Punt CJA, Iannotti N, et al. Relationship of circulating tumor cells to tumor response, progression-free survival, and overall survival in patients with metastatic colorectal cancer. J Clin Oncol. 2008;26(19):3213-3221. doi:10.1200/JCO.2007.15.8923

20. Moon DH, Lindsay DP, Hong S, Wang AZ. Clinical indications for, and the future of, circulating tumor cells. Adv Drug Deliv Rev. 2018;125:143-150. doi:10.1016/j.addr.2018.04.002

21. Mostert B, Kraan J, Bolt-de Vries J, et al. Detection of circulating tumor cells in breast cancer may improve through enrichment with anti-CD146. Breast Cancer Res Treat. 2010;127(1):33-41. doi:10.1007/s10549-010-0879-y

22. Onstenk W, Kraan J, Mostert B, et al. Improved circulating tumor cell detection by a combined EpCAM and MCAM cell search enrichment approach in patients with breast cancer undergoing neoadjuvant chemotherapy. Mol Cancer Ther. 2015;14(3):821-827. doi:10.1158/ 1535-7163.MCT-14-0653

23. Zhang T, Boominathan R, Foulk B, et al. Development of a novel c-MET-Based CTC detection platform. Mol Cancer Res. 2016;14 (6):539-547. doi:10.1158/1541-7786.MCR-16-0011

24. Satelli A, Brownlee Z, Mitra A, Meng QH, Li S. Circulating tumor cell enumeration with a combination of epithelial cell adhesion molecule and cell-surface vimentin-based methods for monitoring breast cancer therapeutic response. Clin Chem. 2015;61(1):259-266. doi:10.1373/clinchem.2014.228122

25. Lu -N-N, Xie M, Wang J, et al. Biotin-triggered decomposable immunomagnetic beads for capture and release of circulating tumor cells. ACS Appl Mater Interfaces. 2015;7(16):8817-8826. doi:10. 1021/acsami.5b01397

26. Coumans FA, Ligthart ST, Uhr JW, Terstappen LW. Challenges in the enumeration and phenotyping of CTC. Clin Cancer Res. 2012;18 (20):5711-5718. doi:10.1158/1078-0432.CCR-12-1585

27. Roh JI, Sung YH, Lee HW. Clinical implications of antitelomeric drugs with respect to the nontelomeric functions of telomerase in cancer. Onco Targets Ther. 2013;6:1161-1166. doi:10.2147/OTT. S50918

28. Macarthur KM, Kao GD, Chandrasekaran S, et al. Detection of brain tumor cells in the peripheral blood by a telomerase promoter-based assay. Cancer Res. 2014;74(8):2152-2159. doi:10.1158/0008-5472. CAN-13-0813 
29. Fizazi K, Morat L, Chauveinc L, et al. High detection rate of circulating tumor cells in blood of patients with prostate cancer using telomerase activity. Ann Oncol. 2007;18(3):518-521. doi:10.1093/ annonc/mdl419

30. Sapi E, Okpokwasili NI, Rutherford T. Detection of telomerase-positive circulating epithelial cells in ovarian cancer patients. Cancer Detect Prev. 2002;26(2):158-167. doi:10.1016/S0361-090X(02)00034-X

31. Soria JC, Gauthier LR, Raymond E, et al. Molecular detection of telomerase-positive circulating epithelial cells in metastatic breast cancer patients. Clin Cancer Res. 1999;5(5):971-975.

32. Gauthier LR, Granotier C, Soria JC, et al. Detection of circulating carcinoma cells by telomerase activity. Br J Cancer. 2001;84 (5):631-635. doi:10.1054/bjoc.2000.1662

33. Hong B, Zu Y. Detecting circulating tumor cells: current challenges and new trends. Theranostics. 2013;3(6):377-394. doi:10.7150/thno.5195

34. Dabighi A, Toghraie D. A new microfluidic device for separating circulating tumor cells based on their physical properties by using electrophoresis and dielectrophoresis forces within an electrical field. Comput Methods Programs Biomed. 2019;185:105147. doi:10.1016/ j.cmpb.2019.105147

35. Gascoyne PR, Shim S, Noshari J, Becker FF, Stemke-Hale K. Correlations between the dielectric properties and exterior morphology of cells revealed by dielectrophoretic field-flow fractionation. Electrophoresis. 2013;34(7):1042-1050. doi:10.1002/elps.201200496

36. Wang XB, Huang Y, Gascoyne PRC, Becker FF, Holzel R, Pethig R. Changes in friend murine erythroleukemia cell-membranes during induced-differentiation determined by electrorotation. Biochimica Et Biophysica Acta-Biomembranes. 1994;1193(2):330-344. doi:10.1016/ 0005-2736(94)90170-8

37. Kim SH, Ito H, Kozuka M, Hirai M, Fujii T. Localization of low-abundant cancer cells in a sharply expanded microfluidic step-channel using dielectrophoresis. Biomicrofluidics. 2017;11:5. doi:10.1063/1.4998756

38. Cheng IF, Huang W-L, Chen T-Y, Liu C-W, Lin Y-D, Su W-C. Antibody-free isolation of rare cancer cells from blood based on $3 \mathrm{D}$ lateral dielectrophoresis. Lab Chip. 2015;15(14):2950-2959. doi:10.1039/C5LC00120J

39. Wang S, Liu K, Liu J, et al. Highly efficient capture of circulating tumor cells by using nanostructured silicon substrates with integrated chaotic micromixers. Angewandte Chemie-Int Ed. 2011;50 (13):3084-3088. doi:10.1002/anie.201005853

40. Miltenyi S, Muller W, Weichel W, Radbruch A. High-gradient magnetic cell-separation with MACS. Cytometry. 1990;11(2):231-238 doi:10.1002/cyto.990110203

41. Giordano A, Gao H, Anfossi S, et al. Epithelial-mesenchymal transition and stem cell markers in patients with HER2-positive metastatic breast cancer. Mol Cancer Ther. 2012;11(11):2526-2534. doi:10.1158/1535-7163.MCT-12-0460

42. Pluim D, Devriese LA, Beijnen JH, Schellens JHM. Validation of a multiparameter flow cytometry method for the determination of phosphorylated extracellular-signal-regulated kinase and DNA in circulating tumor cells. Cytometry Part A. 2012;81A(8):664-671. doi:10.1002/cyto.a.22049

43. Xiong K, Wei W, Jin Y, et al. Biomimetic immuno-magnetosomes for high-performance enrichment of circulating tumor cells. Adv Mater. 2016;28(36):7929-7935. doi:10.1002/adma.201601643

44. Rodriguez PL, Harada T, Christian DA, Pantano DA, Tsai RK, Discher DE. Minimal "Self" peptides that inhibit phagocytic clearance and enhance delivery of nanoparticles. Science. 2013;339 (6122):971-975. doi:10.1126/science.1229568

45. Wu C-H, Huang -Y-Y, Chen P, et al. Versatile immunomagnetic nanocarrier platform for capturing cancer cells. ACS Nano. 2013;7 (10):8816-8823. doi:10.1021/nn403281e

46. Lee S-K, Kim G-S, Wu Y, et al. Nanowire substrate-based laser scanning cytometry for quantitation of circulating tumor cells. Nano Lett. 2012;12(6):2697-2704. doi:10.1021/nl2041707
47. Hong WY, Jeon SH, Lee ES, Cho Y. An integrated multifunctional platform based on biotin-doped conducting polymer nanowires for cell capture, release, and electrochemical sensing. Biomaterials. 2014;35(36):9573-9580. doi:10.1016/j.biomaterials.2014.08.027

48. Zhai -T-T, Ye D, Zhang Q-W, Wu Z-Q, Xia X-H. Highly efficient capture and electrochemical release of circulating tumor cells by using aptamers modified gold nanowire arrays. ACS Appl Mater Interfaces. 2017;9(40):34706-34714. doi:10.1021/acsami.7b11107

49. Stott SL, Hsu C-H, Tsukrov DI, et al. Isolation of circulating tumor cells using a microvortex-generating herringbone-chip. Proc Natl Acad Sci U S A. 2010;107(43):18392-18397. doi:10.1073/ pnas. 1012539107

50. Park MH, Reategui E, Li W, et al. Enhanced isolation and release of circulating tumor cells using nanoparticle binding and ligand exchange in a microfluidic chip. J Am Chem Soc. 2017;139 (7):2741-2749. doi:10.1021/jacs.6b12236

51. Chen W, Weng S, Zhang F, et al. Nanoroughened surfaces for efficient capture of circulating tumor cells without using capture antibodies. ACS Nano. 2013;7(1):566-575. doi:10.1021/nn304719q

52. Adams AA, Okagbare PI, Feng J, et al. Highly efficient circulating tumor cell isolation from whole blood and label-free enumeration using polymer-based microfluidics with an integrated conductivity sensor. J Am Chem Soc. 2008;130(27):8633-8641. doi:10.1021/ ja8015022

53. Dharmasiri U, Balamurugan S, Adams AA, Okagbare PI, Obubuafo A, Soper SA. Highly efficient capture and enumeration of low abundance prostate cancer cells using prostate-specific membrane antigen aptamers immobilized to a polymeric microfluidic device. Electrophoresis. 2009;30(18):3289-3300. doi:10.1002/elps.200900141

54. Zheng S, Lin H, Liu JQ, et al. Membrane microfilter device for selective capture, electrolysis and genomic analysis of human circulating tumor cells. $J$ Chromatogr A. 2007;1162(2):154-161. doi:10.1016/j.chroma.2007.05.064

55. Lin HK, Zheng S, Williams AJ, et al. Portable filter-based microdevice for detection and characterization of circulating tumor cells. Clin Cancer Res. 2010;16(20):5011-5018. doi:10.1158/1078-0432. CCR-10-1105

56. Zheng S, Lin HK, Lu B, et al. 3D microfilter device for viable circulating tumor cell (CTC) enrichment from blood. Biomed Microdevices. 2011;13(1):203-213. doi:10.1007/s10544-010-9485-3

57. Schiro PG, Zhao M, Kuo JS, Koehler KM, Sabath DE, Chiu DT. Sensitive and high-throughput isolation of rare cells from peripheral blood with ensemble-decision aliquot ranking. Angew Chem Int Ed Engl. 2012;51(19):4618-4622. doi:10.1002/anie.201108695

58. Kirby BJ, Jodari M, Loftus MS, et al. Functional characterization of circulating tumor cells with a prostate-cancer-specific microfluidic device. PLoS One. 2012;7(4):e35976. doi:10.1371/journal. pone.0035976

59. Gleghorn JP, Pratt ED, Denning D, et al. Capture of circulating tumor cells from whole blood of prostate cancer patients using geometrically enhanced differential immunocapture (GEDI) and a prostate-specific antibody. Lab Chip. 2010;10(1):27-29. doi:10.1039/B917959C

60. Ma Y, Hao S, Wang S, et al. A combinatory strategy for detection of live CTCs using microfiltration and a new telomerase-selective adenovirus. Mol Cancer Ther. 2015;14(3):835-843. doi:10.1158/ 1535-7163.MCT-14-0693

61. Nagrath S, Sequist LV, Maheswaran S, et al. Isolation of rare circulating tumour cells in cancer patients by microchip technology. Nature. 2007;450(7173):1235-U1210. doi:10.1038/nature06385

62. Diamond E, Lee GY, Akhtar NH, et al. Isolation and characterization of circulating tumor cells in prostate cancer. Front Oncol. 2012;2:131. doi:10.3389/fonc.2012.00131

63. Chung J, Issadore D, Ullal A, Lee K, Weissleder R, Lee H. Rare cell isolation and profiling on a hybrid magnetic/size-sorting chip. Biomicrofluidics. 2013;7(5):54107. doi:10.1063/1.4821923 
64. Campton DE, Ramirez AB, Nordberg JJ, et al. High-recovery visual identification and single-cell retrieval of circulating tumor cells for genomic analysis using a dual-technology platform integrated with automated immunofluorescence staining. BMC Cancer. 2015;15.

65. Park JM, Kim MS, Moon HS, et al. Fully automated circulating tumor cell isolation platform with large-volume capacity based on lab-ona-disc. Anal Chem. 2014;86(8):3735-3742. doi:10.1021/ac403456t

66. Rikkert LG, van der Pol E, van Leeuwen TG, Nieuwland R, Coumans FAW. Centrifugation affects the purity of liquid biopsy-based tumor biomarkers. Cytometry A. 2018;93(12):1207-1212. doi:10.1002/ cyto.a. 23641

67. Hosokawa M, Hayata T, Fukuda Y, et al. Size-selective microcavity array for rapid and efficient detection of circulating tumor cells. Anal Chem. 2010;82(15):6629-6635. doi:10.1021/ac101222x

68. Vona G, Sabile A, Louha M, et al. Isolation by size of epithelial tumor cells - A new method for the immunomorphological and molecular characterization of circulating tumor cells. Am J Pathol. 2000;156(1):57-63. doi:10.1016/S0002-9440(10)64706-2

69. Lederlin M, Tredaniel J, Priollet P. [Why screen for lung cancer in patients with arterial disease?]. J Mal Vasc. 2015;40(6):359-364. French. doi:10.1016/j.jmv.2015.07.001

70. Hartmann C, Patil R, Lin CP, Niedre M. Fluorescence detection, enumeration and characterization of single circulating cells in vivo: technology, applications and future prospects. Phys Med Biol. 2017;63(1):01TR01. doi:10.1088/1361-6560/aa98f9

71. Novak J, Georgakoudi I, Wei X, Prossin A, Lin CP. In vivo flow cytometer for real-time detection and quantification of circulating cells. Opt Lett. 2004;29(1):77-79. doi:10.1364/OL.29.000077

72. Fan ZC, Yan J, Liu GD, et al. Real-time monitoring of rare circulating hepatocellular carcinoma cells in an orthotopic model by in vivo flow cytometry assesses resection on metastasis. Cancer Res. 2012;72 (10):2683-2691. doi:10.1158/0008-5472.CAN-11-3733

73. Suo Y, Gu Z, Wei X. Advances of in vivo flow cytometry on cancer studies. Cytometry A. 2019.

74. Yan J, Fan Z, Wu X, et al. Circulating tumor cells are correlated with disease progression and treatment response in an orthotopic hepatocellular carcinoma model. Cytometry A. 2015;87(11):1020-1028. doi:10.1002/cyto.a.22782

75. Nolan J, Nedosekin DA, Galanzha EI, Zharov VP. Detection of apoptotic circulating tumor cells using in vivo fluorescence flow cytometry. Cytometry Part A. 2019;95A(6):664-671. doi:10.1002/ cyto.a. 23642

76. Pera V, Tan X, Runnels J, Sardesai N, Lin CP, Niedre M. Diffuse fluorescence fiber probe for in vivo detection of circulating cells. J Biomed Opt. 2017;22:3. doi:10.1117/1.JBO.22.3.037004

77. Talasaz AH, Powell AA, Huber DE, et al. Isolating highly enriched populations of circulating epithelial cells and other rare cells from blood using a magnetic sweeper device. Proc Natl Acad Sci U S A. 2009;106(10):3970-3975. doi:10.1073/pnas.0813188106

78. Dharmasiri U, Njoroge SK, Witek MA, et al. High-throughput selection, enumeration, electrokinetic manipulation, and molecular profiling of low-abundance circulating tumor cells using a microfluidic system. Anal Chem. 2011;83(6):2301-2309. doi:10.1021/ac103172y

79. Chan KL, Gascoyne PRC, Becker FF, Pethig R. Electrorotation of liposomes: verification of dielectric multi-shell model for cells. Biochimica Et Biophysica Acta-Lipids Lipid Metabol. 1997;1349 (2):182-196. doi:10.1016/S0005-2760(97)00092-1
80. Vykoukal DM, Gascoyne PRC, Vykoukal J. Dielectric characterization of complete mononuclear and polymorphonuclear blood cell subpopulations for label-free discrimination. Integrative Biol. 2009;1(7):477-484. doi:10.1039/b906137a

81. Huang Y, Yang J, Wang XB, Becker FF, Gascoyne PRC. The removal of human breast cancer cells from hematopoietic CD34 (+) stem cells by dielectrophoretic field-flow-fractionation. J Hematother Stem Cell Res. 1999;8(5):481-490. doi:10.1089/ 152581699319939

82. Moon H-S, Kwon K, Kim S-I, et al. Continuous separation of breast cancer cells from blood samples using multi-orifice flow fractionation (MOFF) and dielectrophoresis (DEP). Lab Chip. 2011;11 (6):1118-1125. doi:10.1039/c01c00345j

83. Cheng IF, Chen T-Y, Lin Y-D, et al. A Novel Dielectrophoresis-Based Microfluidic Chip for Antibody-Free Isolation of Circulating Tumor Cells from Blood. 2015.

84. Cen EG, Dalton C, Li YL, Adamia S, Pilarski LM, Kaler K. A combined dielectrophoresis, traveling wave dielectrophoresis and electrorotation microchip for the manipulation and characterization of human malignant cells. J Microbiol Methods. 2004;58(3):387-401. doi:10.1016/j.mimet.2004.05.002

85. Zhao K, Peng R, Li D. Separation of nanoparticles by a nano-orifice based DC-dielectrophoresis method in a pressure-driven flow. Nanoscale. 2016;8(45):18945-18955. doi:10.1039/C6NR06952E

86. Kang KH, Kang YJ, Xuan XC, Li DQ. Continuous separation of microparticles by size with direct current-dielectrophoresis. Electrophoresis. 2006;27(3):694-702. doi:10.1002/elps.200500 558

87. Bhattacharya S, Chao T-C, Ariyasinghe N, et al. Selective trapping of single mammalian breast cancer cells by insulator-based dielectrophoresis. Anal Bioanal Chem. 2014;406(7):1855-1865. doi:10.1007/s00216-013-7598-2

88. Chuang C-H, Huang Y-W, Wu Y-T. Dielectrophoretic chip with multilayer electrodes and micro-cavity array for trapping and programmably releasing single cells. Biomed Microdevices. 2012;14 (2):271-278. doi:10.1007/s10544-011-9603-x

89. Wu L, Yung L-YL, Lim K-M. Dielectrophoretic capture voltage spectrum for measurement of dielectric properties and separation of cancer cells. Biomicrofluidics. 2012;6:1. doi:10.1063/ 1.3690470

90. Qin Y, Wu L, Schneider T, et al. A Self-Digitization Dielectrophoretic (SD-DEP) chip for high-efficiency single-cell capture, on-demand compartmentalization, and downstream nucleic acid analysis. Angewandte Chemie-Int Ed. 2018;57(35):11378-11383. doi:10.1002/anie.201807314

91. Huang C, Liu H, Bander NH, Kirby BJ. Enrichment of prostate cancer cells from blood cells with a hybrid dielectrophoresis and immunocapture microfluidic system. Biomed Microdevices. 2013;15 (6):941-948. doi:10.1007/s10544-013-9784-6

92. Huang C, Santana SM, Liu H, Bander NH, Hawkins BG, Kirby BJ. Characterization of a hybrid dielectrophoresis and immunocapture microfluidic system for cancer cell capture. Electrophoresis. 2013;34(20-21):2970-2979. doi:10.1002/elps.201370191 


\section{Publish your work in this journal}

Cancer Management and Research is an international, peer-reviewed open access journal focusing on cancer research and the optimal use of preventative and integrated treatment interventions to achieve improved outcomes, enhanced survival and quality of life for the cancer patient.
The manuscript management system is completely online and includes a very quick and fair peer-review system, which is all easy to use. Visit http://www.dovepress.com/testimonials.php to read real quotes from published authors.

Submit your manuscript here: https://www.dovepress.com/cancer-management-and-research-journal 